\title{
Proposta de um modelo de maturidade para sítios de governo eletrônico
}

\section{Proposing a maturity model for electronic government sites}

\author{
Rafael de Mello Lechakoski ${ }^{1}$, Denise Fukumi Tsunoda ${ }^{1}$ \\ ${ }^{1}$ Universidade Federal do Paraná - UFPR, Brasil
}

Autor para correspondência/Mail to: Rafael de Mello Lechakoski rafaelmellol@hotmail.com

Recebido/Submitted: 31 Jul. 2015; Aceito/Approved: 12 Ago. 2015

Copyright (C) 2015 Lechakoski \& Tsunoda. Todo o conteúdo da Revista (incluindo-se instruções, política editorial e modelos) está sob uma licença Creative Commons Atribuição-NãoComercial-Compartilhalgual 3.0 Não Adaptada. Ao serem publicados por esta Revista, os artigos são de livre uso em ambientes educacionais, de pesquisa e não comerciais, com atribuição de autoria obrigatória. Mais informações em http://ojs.c3sl.ufpr.br/ojs2/index.php/atoz/about/submissions\#topyrightNotice.

\begin{abstract}
Resumo
Introdução: Tendo em vista a crescente utilização da tecnologia da informação - em especial a internet - pelo governo como meio de interação com cidadãos, a investigação apresenta estudo bibliográfico acerca de modelos de maturidade para governo eletrônico, abordando os temas de serviços públicos e de maturidade tanto para conceituar a Maturidade em Governo Eletrônico como para propor um modelo de maturidade para sítios de governo eletrônico.

Método: Para atendimento ao propósito da pesquisa efetuou-se coleta intencional de 24 modelos de maturidade para governo eletrônico e se procedeu a análise comparativa entre eles verificando-se suas limitações em relação aos serviços prestados; à acessibilidade; à usabilidade e à integração com redes sociais, considerando-se a realidade brasileira e os requisitos previstos no Modelo de Acessibilidade em Governo Eletrônico (e-MAG).

Resultados: Propõe-se um modelo de maturidade para sítios de governo eletrônico baseado na convergência dos modelos analisados, o qual é composto por quatro estágios voltados à avaliação de requisitos de serviços, acessibilidade, usabilidade e redes sociais. Diferentemente dos demais analisados, o modelo apresentado considera tanto as recomendações de acessibilidade para internet do World Wide Web Consortium (W3C), como aquelas de acessibilidade e usabilidade do governo brasileiro (e-MAG). Em cada estágio proposto apresentam-se exemplos de requisitos que podem ser avaliados e, potencialmente, transformados em indicadores.

Conclusão: A utilização de um modelo para avaliar a maturidade em sítios de governo eletrônico evidencia a situação em que o sítio se encontra em relação ao que é esperado em cada estágio e qual é a linha conceitual de evolução dentro do modelo de maturidade, que reflete em melhorias a seus usuários ou cidadãos de maneira geral.
\end{abstract}

Palavras-chave: Modelo de maturidade; Governo eletrônico; Serviços públicos

\begin{abstract}
Introduction: Given the increasing use of information technology, especially the Internet, by the government - as a means of interaction with citizens - the research presents a bibliographical study about maturity models for electronic government, approaching the issues of Public Services to conceptualize Electronic Government and Maturity in order to propose a maturity model for eletronic government websites.

Method: An intentional collection of 24 models of maturity for electronic government was used and a comparative analysis was performed to seek for limitations in relation to the services, accessibility, usability and integration with social networks regarding a Brazilian reality and the e-MAG model. Results: It proposes a maturity model for electronic government sites, based on the convergence of the selected models, which consists of four stages focused on evaluating service requirements, accessibility, usability and social networking. Unlike the others, the proposed model takes into account both the accessibility guidelines for Internet World Wide Web Consortium (W3C), as well as those of accessibility and usability of the Brazilian government (e-MAG). Each stage of this model includes some examples of requirements that can be evaluated and, potentially, converted into indicators Conclusions: The use of a model to assess the maturity of electronic government sites could demonstrate the current situation of the e-gov site in relation to what is expected at each stage, and what is the conceptual line of evolution in the maturity model, bringing improvements for its users or the general public.
\end{abstract}

Keywords: Maturity model; E-government; Public services

\section{INTRODUÇÃO}

A popularidade do computador, o acesso às informações, a universalização dos meios de comunicação em conjunto com a expansão globalizada da internet possibilitou o surgimento da sociedade de informações e posteriormente a sociedade em rede (Guerreiro, 2006, p. 172).

A partir do fenômeno da globalização, as relações entre governo e cidadãos têm se modificado, originando novos padrões sociais de expressão e organização, que impactam na forma da prestação de informações e serviços e acompanham uma crescente demanda que não está mais vinculada a um espaço geográfico delimitado.

O desenvolvimento tecnológico afetou também a gestão da Administração e, mais especificamente, a utilização de sistemas de informação. Uma nova forma de organização pode ser entendida como uma sociedade em rede, ou seja, uma estrutura social baseada em redes de informação em que o cidadão é o centro das atividades (Castells, 2002). 
Entretanto, a ausência de uma prática que considere o cidadão como fomentador de demandas faz com que o governo tenha dificuldades na percepção do alinhamento das suas iniciativas com as necessidades dos cidadãos.

As tecnologias da informação e comunicação apresentam-se como uma oportunidade aos cidadãos para que serviços que antes eram prestados exclusivamente de forma presencial passem a ser oferecidos por meio de canais digitais, configurando rapidez, eficiência e aproximação da relação Estado-sociedade (Barbosa, 2010).

A internet tornou-se uma ferramenta para agilizar os processos e promover a transparência nas atividades do governo que, a partir de 2002 - com o surgimento da Lei de Responsabilidade Fiscal - definiu os meios pelos quais todos os níveis de governo são obrigados a disponibilizar suas contas públicas.

Um exemplo da utilização de sistemas de informação disponibilizados na internet é o projeto chamado governo eletrônico (e-Gov), destinado a capacitar o setor público a enfrentar os desafios desta sociedade da Era da Informação. Neste, e para o atendimento aos cidadãos, se propõe o desenvolvimento de portais na internet que funcionem como balcões virtuais de informação e atendimento na prestação de serviços. De forma mais específica governo eletrônico é um conjunto de serviços oferecidos pelo governo por meios eletrônicos procurando a ampliação da cidadania, aumento da transparência da gestão e a participação dos cidadãos no acesso e fiscalização às informações e serviços públicos (Chahim, Cunha, Knight, \& Pinto, 2004).

O "governo eletrônico" envolve os processos do órgão ao qual pertence, portanto passível de avaliação de maturidade que pode ser entendida como o estado dos processos chegados ao seu completo desenvolvimento. Desta forma a maturidade é caracterizada como evolutiva e objetiva a melhoria dos processos nas organizações, o que influencia diretamente na qualidade de seu negócio. Para mensurar a perspectiva evolutiva, são definidos níveis de maturidade nos quais há indicações do desempenho da organização em determinados conjuntos de disciplinas para cada um deles (Carnegie Mellon University, 2006).

Dado este contexto, o objetivo da investigação é a concepção de um modelo de maturidade para sítios de governo eletrônico baseado na análise de modelos já existentes com a inclusão de requisitos para prestação de serviços, acessibilidade e usabilidade na internet - conforme recomendação do governo brasileiro por meio do Modelo de Acessibilidade em Governo Eletrônico (e-MAG) - e criação de critérios de interação com redes sociais. Em cada estágio proposto apresentam-se exemplos de requisitos que podem ser avaliados e transformados em indicadores.

\section{SERVIÇOS PÚBLICOS E OS MODELOS DE MATURIDADE}

Serviços públicos são tidos como de peculiar interesse da Administração e sua prestação é a principal atribuição do governo, podendo ser encarada como seu motivo para existir (Araújo, 2007). Para Meirelles (1996) serviços públicos são aqueles prestados à comunidade pela Administração no entendimento que sua utilização é necessária à coletividade. Já na definição de Di Pietro (2012, p. 106), serviço público é tido como “toda atividade material que a lei atribui ao Estado para que a exerça diretamente ou por meio de seus delegados, com o objetivo de satisfazer concretamente às necessidades coletivas, sob regime jurídico único total ou parcialmente público".

Em busca pela melhoria da prestação dos serviços públicos aos cidadãos a Administração Pública vem investindo em recursos de Tecnologia da Informação como sistemas de informação e internet (Rezende, 2012; Santos, 2002).

Maturidade é a perfeição de um plano, projeto ou empresa que se calculou e em que se refletiu o tempo necessário. Atingir a maturidade significa atingir o ponto no qual a evolução esperada foi alcançada com o objetivo de melhorias. O Software Engineering Institute (SEI), da Carnegie Mellon University indica três dimensões críticas em que uma organização deve focar esforços para melhorar seus negócios, são elas: pessoas, procedimentos e métodos, e ferramentas e equipamentos (Carnegie Mellon University, 2006). A partir da premissa de que o processo utilizado para desenvolver e manter um sistema ou produto influencia diretamente sua qualidade impulsionou o Instituto a definir os Capability Maturity Models (CMMs) - ou Modelos de Maturidade de Capacitação - que objetivam a melhoria dos processos nas organizações, unificando alguns dos modelos já existentes, conforme o detalhamento a seguir.

Estes modelos, de acordo com Paula Filho (2011, p. 68) "contêm os elementos essenciais de processos eficazes para uma ou mais disciplinas e descrevem um caminho de melhoria evolutiva que parte de processos imaturos e ad hoc, até chegar a processos maduros e disciplinados". Estes elementos são referências para avaliação da maturidade dos processos das organizações por meio da comparação entre as práticas reais observadas na organização e aquelas recomendadas pelo modelo.

Vários CMMs foram desenvolvidos para atender a várias disciplinas tais como: a Engenharia de Sistemas, a Engenharia de Software, a Aquisição de Software, a Gestão e desenvolvimento de força de trabalho, e o Desenvolvimento Integrado de Processo e Produto (IPPD). Tal diversidade tornou necessária a utilização de diferentes modelos para atender a diferentes áreas dentro de uma organização, tornando-se um procedimento 
que despendia muitos esforços. A partir deste problema foi construído um modelo que unificava estes modelos, surgindo então o Capability Maturity Model Integration (CMMI) (Carnegie Mellon University, 2006). Na definição da SEI (Carnegie Mellon University, 2006, p. 9) o CMMI "possibilita abordar melhoria e avaliação de processos utilizando duas representações diferentes: contínua e por estágios”. A representação contínua possibilita o desenvolvimento individual ou coletivo de áreas de processo selecionadas para a melhoria dos processos correlatos e utiliza níveis de capacidade para caracterizar a melhoria da área ou processo. A representação por estágios é realizada a partir conjuntos de áreas de processo pré-definidas para a definição de como executar melhorias. Este caminho é caracterizado por níveis de maturidade nos quais cada um contém áreas de processos que definem diferentes comportamentos organizacionais.

O caminho evolutivo que demonstra a melhoria dos processos das organizações é representado no CMMI por níveis, que também definem sua classificação dentre estes mediante avaliação da organização e seus processos (Carnegie Mellon University, 2006).

De acordo com a definição da SEI (Carnegie Mellon University, 2006, p. 37) um nível de maturidade de uma organização é "uma indicação do desempenho da organização em uma determinada disciplina ou conjunto de disciplinas”. Existem cinco níveis de maturidade e cada nível representa o grau de maturidade de acordo com suas especificações atendidas, que em cada nível são observadas:

a) Inicial: possui processos informais e caóticos. Não apresenta um ambiente estável para o apoio a processos e a competência pessoal influencia para o sucesso;

b) Gerenciado: os processos são planejados e executados de acordo com uma política, a partir das experiências anteriores. As saídas são controladas e geradas com recursos adequados;

c) Definido: Os processos são documentados e claramente compreensíveis, descritos em padrões, procedimentos, ferramentas e métodos. A base para as atividades é referenciada em processos-padrão;

d) Gerenciado quantitativamente: cada processo possui um objetivo quantitativo para alcançar a qualidade esperada, bem como a organização estabelece objetivos de desempenho;

e) Em otimização: a organização busca a melhoria contínua de seus processos para maior excelência em seus ativos.

Cada um dos níveis é a base necessária para os seguintes, ou seja, é necessário satisfazer minimamente as metas genéricas de um nível para alcançar o próximo, em um trabalho evolutivo (Paula Filho, 2011).

\section{GOVERNO ELETRÔNICO E UM PANORAMA DOS MODELOS DE MATURIDADE}

Na definição de Ferrer e Santos (2004, p. xvii) pode-se chamar de governo eletrônico "o conjunto de serviços e o acesso à informação que o governo oferece aos diferentes atores da sociedade civil por meios eletrônicos” e se pode considerar o acesso à informação como um serviço oferecido. Portanto, o conceito de governo eletrônico pode ser consolidado como "o conjunto de serviços que o governo oferece aos diferentes atores da sociedade civil por meios eletrônicos” (Ferrer \& Santos, 2004, p. xvii).

Com a consolidação dos sistemas de informação, possibilitada pelos avanços na área da informática e da tecnologia da informação (TI) das últimas décadas, o fenômeno da internet conquistou espaço dentro da administração pública por proporcionar a comunicação entre cidadãos e organização a um baixo custo, com velocidade e facilidade, elementos que atendem ao princípio da eficiência observado no modelo de gestão legado (Zugman, 2006).

A utilização desta tecnologia pelos governos de diversos países foi denominada e-Government ou governo eletrônico (também conhecida por e-Gov) e promoveu uma revolução em alguns aspectos do relacionamento com cidadãos. Esta revolução foi possível com os avanços da TI, dentre eles os avanços dos equipamentos eletrônicos, tornados cada vez mais potentes e os avanços da rede de comunicações global (a internet), que possibilitou o compartilhamento de informações entre os indivíduos de qualquer lugar (Laudon \& Laudon, 2013; Zugman, 2006). Pode-se considerar o governo eletrônico como reflexo da globalização na sociedade da informação.

Considera-se que a área pública deve atender a todos os cidadãos com a prestação de serviços diversificados, com a garantia do amplo acesso. A internet pode facilitar a este propósito, entretanto é necessário atendimento, justamente, dos preceitos de acessibilidade (Zugman, 2006).

Existem diversos modelos de maturidade para governo eletrônico. Entretanto, cada modelo avalia critérios específicos para o contexto de determinada localidade ou realidade, apresentando diferentes níveis de maturidade e diferentes especificações dentro de cada nível.

A seguir são elencados os modelos coletados de maneira intencional conforme encontrados na literatura e alinhados ao escopo da pesquisa, arrolados em ordem cronológica decrescente: 
Alhomod e Shafi (2012): modelo de maturidade de quatro estágios de $e$-Gov ("presença na internet", "interação entre o cidadão e o governo", "transação completa através da internet" e "integração de serviços").

Lee e Kwak (2012): modelo de maturidade de cinco estágios de $\boldsymbol{e}$-Gov ("condições iniciais", "transparência de dados", "participação aberta", "colaboração aberta" e "engajamento onipresente") que se concentra em um governo aberto com utilização de mídias sociais e ferramentas da internet 2.0. O modelo foi desenvolvido com base em estudos de caso de agências da Administração de Saúde dos Estados Unidos.

Organização das Nações Unidas (ONU) (United Nations, 2012): modelo de maturidade de cinco estágios de e-Gov ("informações emergentes", "serviços de informação melhorados", "interação", "serviços transacionais" e "serviços interligados"), usado para classificar os países membros da ONU.

Chen, Yan, e Mingins (2011): modelo de maturidade de três estágios de e-Gov ("catálogo", "transação" e "integração vertical"), proposto com base em pesquisa teórica e experiência dos autores em e-Govs regionais na China.

Kim e Grant (2010): modelo de maturidade de cinco estágios de $e$-Gov ("presença na internet", "interação", "transação", "integração" e "melhoria contínua").

Almazan e Gil Garcia (2008): modelo de maturidade de seis estágios para e-Gov ("presença", "informação", "interação", "transação", "integração" e "participação política"), utilizado no México em uma análise sistemática de 32 sítios estaduais. Os autores concluíram que os sítios estaduais mexicanos estão nos estágios iniciais de governo eletrônico.

Shahkooh, Saghafi, e Abdollahi (2008): modelo de maturidade de cinco estágios de $e$-Gov ("presença online", "interação", "operação", "governo eletrônico totalmente integrado e transformado" e "democracia digital").

Cisco Systems Inc. (2008): modelo de maturidade de três estágios de $e$-Gov ("interação da informação", "eficiência em transações" e "central de transformação dos cidadãos").

Andersen e Henriksen (2002): modelo de maturidade de quatro estágios de e-Gov ("cultura", "extensão", "maturidade" e "revolução"), utilizado na Dinamarca em uma avaliação de 110 agências do país.

Siau e Long (2005): modelo de maturidade de cinco estágios de $e$-Gov ("presença na internet", "interação", "transação", "transformação" e "e-democracia").

Reddick (2004): modelo de maturidade de dois estágios de $e$-Gov ("catalogação" e "transações"), utilizado no contexto dos Estados Unidos e buscando examinar o estágio de e-Gov municipal das cidades americanas naquela ocasião. O autor concluiu que os sítios estão no primeiro estágio de maturidade.

West (2004): modelo de maturidade de quatro estágios de e-Gov ("quadro de avisos", "serviço parcial de entrega", "portal ou balcão" e "democracia interativa"), utilizado em uma análise de conteúdo de sítios governamentais estaduais e federais dos Estados Unidos. Isto incluiu 1.813 sítios do governo, em 2000, e um estudo de acompanhamento de 1680 sítios do governo em 2001. Os autores concluíram que muitas agências governamentais têm dominado a primeira e a segunda fase, enquanto alguns sítios do governo alcançaram a $3^{\mathrm{a}} \mathrm{e} 4^{\mathrm{a}}$ fase.

Rohleder e Jupp (2003): modelo de maturidade de cinco estágios de $e$-Gov ("presença online", "capacidade básica", "disponibilidade do serviço", "maturidade de entrega" e "transformação de serviços".). Os autores realizaram, em 2000, um survey sobre desenvolvimento de políticas de $e$-Gov e, a partir dos resultados, caracterizou a progressão das ações de governo eletrônico em um conjunto de três estágios (informacional, interativo e transacional). Mais tarde o modelo foi estendido para incorporar a ideia de transformação dos processos governamentais, tendo como foco o cidadão. O modelo foi utilizado para classificar os e-Govs do Canadá, Cingapura, Estados Unidos, Dinamarca, Austrália, Finlândia, Hong Kong, Reino Unido, Bélgica, Alemanha, Irlanda, França, Holanda, Espanha, Japão, Noruega, Itália, Malásia, México, Portugal, Brasil e África do Sul.

Chandler e Emanuels (2002): modelo de maturidade de quatro estágios de e-Gov ("informação", "interação", "transação" e "integração").

Moon (2002): modelo de maturidade de cinco estágios de $e$-Gov ("simples divulgação de informações", "comunicação bidirecional", "serviços e transações financeiras", "integração" e "participação política") com base no estado atual das iniciativas municipais de $e$-Gov nos Estados Unidos a partir de dados de 2000 pesquisas de e-Gov em municípios.

Netchaeva (2002): modelo de maturidade de cinco estágios de e-Gov ("sítios online", "FAQs e sistemas de e-mail", "fóruns e pesquisas de opinião", "serviços online" e "portais únicos").

National Audit Office (NAO) (United Kingdon, 2002): modelo de maturidade de cinco estágios de e-Gov ("sítio básico", "publicação eletrônica", "e-publicação", "transacional" e "governo eletrônico único").

Windley (2002): modelo de maturidade de quatro estágios de $e$-Gov ("sítio simples", "governo online", "governo integrado" e "governo transformado"), aplicado ao sítio governamental "Utah.gov" nos Estados Unidos e o autor 
concluiu que o sítio está solidamente no segundo estágio de maturidade.

Hiller e Belanger (2001): modelo de maturidade de cinco estágios de $e$-Gov ("informação", "comunicação bidirecional", "transação", "integração" e "participação").

Howard (2001): modelo de maturidade de três estágios de e-Gov ("publicar", "interagir" e "transacionar").

Layne e Lee (2001): modelo de maturidade de quatro estágios de e-Gov ("catálogo", "transação", "integração vertical" e "integração horizontal"), com base em observações a respeito de iniciativas de governo eletrônico nos Estados Unidos.

Wescott (2001): modelo de maturidade de seis estágios de $e$-Gov ("a criação de um sistema de e-mail e rede interna", "possibilitar o acesso interorganizacional e do público à informação", "permitir a comunicação bidirecional", "permitir a troca de valor", "democracia digital" e "governo conjunto") que se concentra no desenvolvimento do governo eletrônico na região da Ásia. O autor concluiu que a maioria dos países asiáticos ainda está nas fases iniciais do $e-G o v$.

Baum e Di Maio, do Gartner Group (Baum \& Di Maio, 2000): modelo de maturidade de quatro estágios de $e$-Gov ("presença na internet", "interação", "transação" e "transformação").

Deloitte Touche (2000): modelo de maturidade de seis fases de $e$-Gov ("publicação de informação", "transação oficial bidirecional", "portal multiuso", "portal personalizado", "agrupamento de serviços comuns" e "completa integração e transações empresariais"). O modelo foi utilizado na Austrália, Canadá, Nova Zelândia, Reino Unido e Estados Unidos e os autores concluíram que a maioria dos governos estão, pelo menos, na primeira fase.

Estes modelos são aplicados conforme situação da realidade em que foram desenvolvidos, sendo necessárias adaptações para aplicação em realidades não previstas e abordadas.

\section{MÉTODO}

A partir do estudo dos modelos de maturidade foi possível desenvolver o conceito para elaboração do modelo de maturidade para sítios de governo eletrônico proposto. Por meio do estudo e comparação destes modelos de maturidade foi elaborado um quadro demonstrando os estágios de cada modelo (Quadro 1).

\begin{tabular}{|c|c|c|c|c|c|c|c|}
\hline Modelos & Estágio 1 & Estágio 2 & Estágio 3 & Estágio 4 & \begin{tabular}{|l|l|l|} 
Estágio 5 \\
\end{tabular} & Estágio 6 & $\mathrm{~N}$. \\
\hline Alhomod e Shafi (2012) & $\begin{array}{l}\text { Presença na inter- } \\
\text { net }\end{array}$ & $\begin{array}{l}\text { Interação entre o cidadāo } \\
\text { e o governo }\end{array}$ & $\begin{array}{l}\text { Transação completa } \\
\text { através da internet }\end{array}$ & $\begin{array}{ll}\text { Integração } & \text { de } \\
\text { serviços } & \end{array}$ & $\mathrm{X}$ & $\mathrm{X}$ & 4 \\
\hline Lee e Kwak (2012) & Condiçōes iniciais & Transparência de dados & Participação aberta & Colaboração aberta & $\begin{array}{l}\text { Engajamento } \\
\text { onipresente }\end{array}$ & $\mathrm{x}$ & 5 \\
\hline United Nations (2012) & $\begin{array}{l}\text { Informaçōes emer- } \\
\text { gentes }\end{array}$ & $\begin{array}{l}\text { Serviços de informação } \\
\text { melhorados }\end{array}$ & Interação & $\begin{array}{l}\text { Serviços transa- } \\
\text { cionais }\end{array}$ & $\begin{array}{l}\text { Serviços interliga- } \\
\text { dos }\end{array}$ & $\mathrm{x}$ & 5 \\
\hline Chen, Yan e Mingins (2011) & Catálogo & Transaçāo & Integração vertical & & $\mathrm{x}$ & $\mathrm{x}$ & 3 \\
\hline Kim e Grant (2010) & $\begin{array}{l}\text { Presença na inter- } \\
\text { net }\end{array}$ & Interaçầo & Transação & Integração & Melhoria contínua & $\mathrm{x}$ & 5 \\
\hline Almazan e Gil-Garcia (2008) & Presença & Informação & Interaçāo & Transação & Integração & Participação & 6 \\
\hline $\begin{array}{l}\text { Shahkooh, Saghafi e Abdollahi } \\
\text { (2008) }\end{array}$ & Presença online & Interação & Operação & $\begin{array}{l}\text { Governo eletrônico } \\
\text { totalmente inte- } \\
\text { grado e transfor- }\end{array}$ & Democracia digital & $\mathrm{X}$ & 5 \\
\hline Cisco Systems Inc. (2007) & $\begin{array}{l}\text { Interaçāo da infor- } \\
\text { maçâ }\end{array}$ & Eficiência em transaçōes & $\begin{array}{l}\text { Central de transformação } \\
\text { dos cidadãos }\end{array}$ & $\mathrm{x}$ & $\mathrm{x}$ & $\mathrm{x}$ & 3 \\
\hline Andersen e Henriksen (2006) & Cultura & Extensão & Maturidade & Revolução & $\mathrm{x}$ & $\mathrm{x}$ & 4 \\
\hline Siau e Long (2005) & $\begin{array}{l}\text { Presença na inter- } \\
\text { net }\end{array}$ & Interação & Transação & Transformação & e-democracia & $\mathrm{x}$ & 5 \\
\hline Reddick (2004) & Catalogação & Transaçōes & $\mathrm{x}$ & $\mathrm{x}$ & $\mathrm{x}$ & $\mathrm{x}$ & 2 \\
\hline West (2004) & Quadro de avisos & Serviço parcial de entrega & Portal ou balcão & $\begin{array}{l}\text { Democracia intera- } \\
\text { tiva }\end{array}$ & $\mathrm{x}$ & $\mathrm{x}$ & 4 \\
\hline Rohleder e Jupp (2003) & Presença online & Capacidade básica & $\begin{array}{l}\text { Disponibilidade } \\
\text { serviço }\end{array}$ & $\begin{array}{l}\text { Maturidade de en- } \\
\text { trega }\end{array}$ & $\begin{array}{l}\text { Transformação de } \\
\text { serviços }\end{array}$ & $\mathrm{x}$ & 5 \\
\hline Chandler e Emanuel (2002) & Informação & Interaçāo & Transaçāo & Integração & $\mathrm{x}$ & $\mathrm{x}$ & 4 \\
\hline Moon (2002) & $\begin{array}{l}\text { Simples divulgação } \\
\text { de informaçōes }\end{array}$ & $\begin{array}{l}\text { Comunicação bidire- } \\
\text { cional }\end{array}$ & $\begin{array}{l}\text { Serviços e transaçōes fi- } \\
\text { nanceiras }\end{array}$ & Integração & $\begin{array}{l}\text { Participação } \\
\text { política }\end{array}$ & $\mathrm{x}$ & 5 \\
\hline Netchaeva (2002) & Sítios online & $\begin{array}{l}\text { FAQ'S e sistemas de e- } \\
\text { mail }\end{array}$ & $\begin{array}{l}\text { Fóruns e pesquisas de } \\
\text { opinião }\end{array}$ & Serviços online & Portais únicos & $\mathrm{x}$ & 5 \\
\hline United Kingdon (2002) & Sítio básico & Publicação eletrônica & e-publicação & Transacional & $\begin{array}{l}\text { Governo eletrônico } \\
\text { único }\end{array}$ & $\mathrm{x}$ & 5 \\
\hline Windley (2002) & Sítio simples & Governo online & Governo integrado & $\begin{array}{l}\text { Governo transfor- } \\
\text { mado }\end{array}$ & $\mathrm{x}$ & $\mathrm{x}$ & 4 \\
\hline Hiller e Belanger (2001) & Informação & $\begin{array}{l}\text { Comunicação bidire- } \\
\text { cional }\end{array}$ & $\begin{array}{l}\text { Transação completa } \\
\text { através da internet }\end{array}$ & Integração & Participação & $\mathrm{x}$ & 5 \\
\hline Howard (2001) & Publicar & Interagir & Transacionar & & $\mathrm{x}$ & $\mathrm{x}$ & 3 \\
\hline Layne e Lee (2001) & Catálogo & Transaçāo & Integração vertical & $\begin{array}{l}\text { Integração hori- } \\
\text { zontal }\end{array}$ & $\mathrm{x}$ & $\mathrm{x}$ & 4 \\
\hline Wescott (2001) & $\begin{array}{l}\text { Criação de um sis- } \\
\text { tema de e-mail e } \\
\text { rede interna }\end{array}$ & $\begin{array}{l}\text { Possibilitar o acesso } \\
\text { inter-organizacional e do } \\
\text { público à informaçāo }\end{array}$ & $\begin{array}{l}\text { Permitir a comunicação } \\
\text { bidirecional }\end{array}$ & $\begin{array}{l}\text { Permitir a troca de } \\
\text { valor }\end{array}$ & Democracia digital & Governo conjunto & 6 \\
\hline Baum e Di Maio (2000) & $\begin{array}{l}\text { Presença na inter- } \\
\text { net }\end{array}$ & Interação & Transaçāo & Transformaçāo & $\mathrm{x}$ & $\mathrm{x}$ & 4 \\
\hline Deloitte e Touche (2000) & $\begin{array}{l}\text { Publicação de infor- } \\
\text { mação }\end{array}$ & $\begin{array}{l}\text { Transação oficial bidire- } \\
\text { cional }\end{array}$ & Portal multiuso & $\begin{array}{l}\text { Portal personali- } \\
\text { zado }\end{array}$ & $\begin{array}{l}\text { Agrupamento de } \\
\text { serviços comuns }\end{array}$ & $\begin{array}{l}\text { Completa inte- } \\
\text { gração e transaçōes } \\
\text { empresariais }\end{array}$ & 6 \\
\hline
\end{tabular}

Quadro 1. Comparativo dos estágios entre modelos de maturidade Fonte: os autores (2015).

Estes 24 modelos de maturidade serviram de base para o desenvolvimento do modelo de maturidade para sítios de governo eletrônico proposto. Com a compilação dos objetivos dos modelos e a convergência de seus estágios foi possível desenvolver um modelo que sintetizasse estes conceitos levantados. 
No modelo proposto, diferentemente dos outros analisados, são consideradas as recomendações de acessibilidade para internet do órgão responsável por estabelecer políticas de acesso, o World Wide Web Consortium (W3C), bem como as recomendações de acessibilidade e usabilidade do governo brasileiro por meio do Modelo de Acessibilidade em Governo Eletrônico (e-MAG) e, ainda, a inserção do governo eletrônico em redes sociais alinhada à política de compartilhamento do conhecimento. Desta forma o modelo avalia funcionalidade em quatro áreas de atuação:

a) serviços: avalia o nível de automatização e integração na prestação de serviços pela internet baseado nos modelos de maturidade e nas responsabilidades de prestação de serviços pelos municípios;

b) acessibilidade: avalia o nível de acessibilidade do sítio baseado em orientação do consórcio W3C;

c) usabilidade: avalia a facilidade de uso dos sítios e seu comportamento como previsível baseado em recomendações do governo federal para governo eletrônico;

d) redes sociais: avalia a inserção dos órgãos em redes sociais e a utilização destas ferramentas como suporte à interação com cidadãos, oferta de serviços e base de conhecimento.

Cada estágio do modelo considera a implementação destes quatro itens de maneira incremental de acordo com seu nível (de 1 a 4 ) exemplificado a seguir.

\section{Modelo de maturidade: proposta}

Como consequência dos procedimentos metodológicos e da análise dos modelos de maturidade para governo eletrônico foi possível conceber o presente modelo de maturidade para governo eletrônico o qual possui quatro estágios numerados de 1 a 4 (Figura 1).

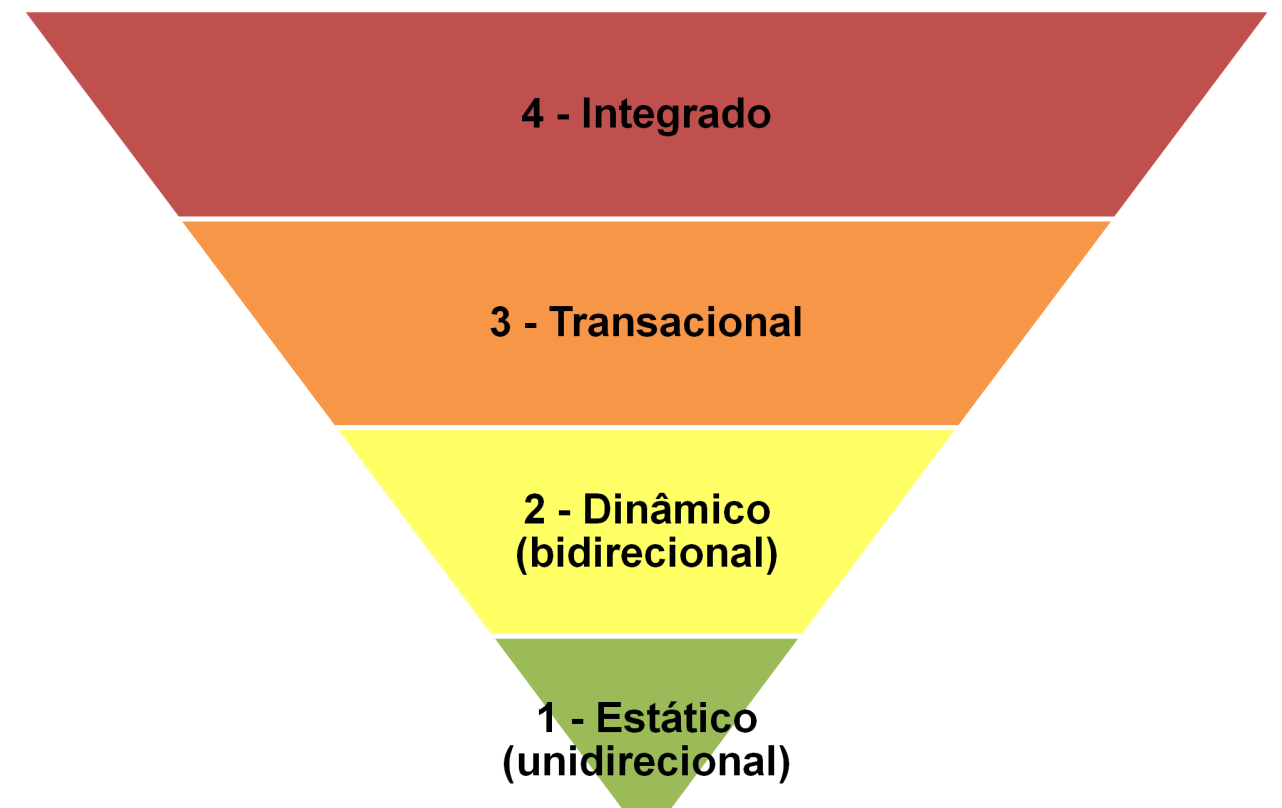

Figura 1. Modelo de maturidade para governo eletrônico.

Fonte: os autores (2015).

O modelo é representado por uma pirâmide invertida, sendo que em sua base encontra-se o primeiro estágio de maturidade (Estático) que contempla as funcionalidades mais básicas dentre os estágios, sendo, portanto, a ponta mais estreita da pirâmide. O segundo estágio, Dinâmico, é identificado por uma parte maior da pirâmide em relação ao primeiro, o que significa que este estágio engloba as funcionalidades do primeiro estágio e contempla outras funcionalidades mais específicas. Nesta lógica seguem o terceiro (Transacional) e quarto (Integrado) estágios, destacando que são mais robustos que seus anteriores pela representação de um maior tamanho na pirâmide invertida. Desta forma, o quarto e último estágio é o mais específico e complexo do modelo, pois incorpora as funcionalidades dos estágios anteriores e ainda contempla novos requisitos.

\section{Estágio 1: Estático (unidirecional)}

Neste estágio os sítios se preocupam em disponibilizar informações limitadas em escopo, de característica básica e estática, caracterizadas pela difusão de informações sobre os mais diversos órgãos e departamentos dos diversos níveis de governo. As páginas tomam a forma de catálogo de endereços dos diversos órgãos do 
governo, contendo links para outras páginas do órgão ou para outros níveis da administração. É possível efetuar download de arquivos anexados ao sítio (não indexados) e realizar buscas em palavras presentes nas páginas. Entretanto, existem melhorias a fazer no que se refere à atualização dos sítios e à acessibilidade para o usuário.

\section{Estágio 2: Dinâmico (bidirecional)}

No segundo estágio as informações dos sítios estão categorizadas e provêm de bases de dados, não apenas texto estático inserido diretamente nas páginas. O sítio, neste estágio, é regularmente atualizado e as buscas de conteúdos são mais complexas e efetivas. Inclui a disponibilização de meio para contato e formulários para interação com os cidadãos, como perguntas e respostas, e mesmo algumas solicitações ou agendamentos de serviços, desta forma o sítio passa a receber informações e dados por parte dos usuários (cidadãos, empresas ou outros órgãos). Um dos problemas observados neste estágio é a disponibilização de informações redundantes e/ou burocráticas por não possuir mecanismos de classificação de conteúdo, portanto, não centradas no usuário.

\section{Estágio 3: Transacional}

As transações se tornam mais complexas, e o governo começa a se transformar por meio da interação com os cidadãos. Neste estágio de maturidade os usuários podem realizar transações on-line, como pagamento de taxas e impostos ou requisitar serviços como matrículas, marcação de consultas, compras, carteira de identidade, passaporte entre outros e estas ações podem ser executadas tanto por meio do cartão de crédito ou uso de contas bancárias. Os serviços são organizados de acordo com seu propósito não existindo fronteiras de departamentos e secretarias. Tal configuração representa que cada serviço é disponibilizado por funções ou temas, e não segundo a divisão real do governo em ministérios, secretarias, departamentos ou outras divisões. As transações on-line são realizadas de maneira segura e envolve alto grau de integração arquitetural entre os sistemas de informação existentes no órgão.

\section{Estágio 4: Integrado}

No último estágio é desenvolvido um portal de convergência de todos os serviços prestados pelo governo passando por uma redefinição de funcionalidades e responsabilidades, e possibilitando sua integração. Neste estágio a identidade do órgão que presta o serviço se torna irrelevante, pois a informação se encontrará organizada de acordo com as necessidades do usuário. As ações neste estágio envolvem a transformação do próprio governo em uma rede integrada que reponde às necessidades do cidadão. É o conceito de um portal que contém: conexão horizontal entre os órgãos; conexão vertical entre as esferas de governo; infraestrutura integrada por meio de padrões arquiteturais e de interoperabilidade; conexão entre governo e cidadãos; e conexão entre os stakeholders -- governo, setor privado, instituições acadêmicas e organizações não governamentais. Também possui integração com outras mídias, como redes sociais, em que os conteúdos postados pelos usuários são categorizados e transformados em banco de conhecimento.

Para possibilitar a classificação do objeto (sítio) analisado dentro de cada estágio, podem existir requisitos inerentes às funcionalidades necessárias àquele estágio. Estes requisitos podem ser representados em forma de indicadores a partir dos quais se pontua o grau de atendimento das funcionalidades disponíveis no sítio. As funcionalidades analisadas podem ser agrupadas de acordo com a temática avaliada com a finalidade de avaliar características complementares dentro do contexto do governo eletrônico conforme os grupos: serviços, acessibilidade, usabilidade e redes sociais anteriormente citados.

Cada grupo possui requisitos ou indicadores de acordo com a similaridade entre si e com o grupo tendo por objetivo avaliar itens específicos dos sítios para governo eletrônico. Na sequência são apresentados exemplos de requisitos avaliados em cada grupo, seus detalhamentos e a(s) fonte(s) pesquisadas para que fossem inseridos no modelo proposto.

\section{Requisitos agrupados por estágios do modelo de maturidade proposto}

\section{Estágio 1}

a) Grupo: Serviço

fontes: Ferrer e Santos (2004); Laudon e Laudon (2013); Zugman (2006); modelos analisados

- Requisito: Informações sobre o órgão;

- Detalhamento: A página possui informações referentes ao órgão. Ex.: Estrutura, horário de funcionamento e endereço.

b) Grupo: Acessibilidade

fontes: WCAG (2014); Brasil (2014) 
- Requisito: Página com título;

- Detalhamento: As páginas Web têm títulos que descrevem o tópico ou a finalidade. Ex.: O título que aparece no navegador representa a finalidade da página.

c) Grupo: Usabilidade

fontes: Brasil (2014b); Brasil (2009)

- Requisito: Página inicial condizente com a finalidade do órgão;

- Detalhamento: A página inicial do portal deve deixar claro o que é o sítio, seu objetivo e as informações e serviços nele disponíveis. Ex.: A página inicial possui a descrição de sua competência, as atividades desenvolvidas e os serviços disponíveis.

d) Grupo: Rede social

fontes: Dziekaniak (2012); modelos analisados

- Requisito: Inserção do governo nas redes sociais por meio de perfil ou página;

- Detalhamento: O órgão possui uma conta em rede social mantendo uma página como forma de comunicação com os cidadãos. Ex.: Página da Prefeitura Municipal de Curitiba no Facebook - https://ptbr.facebook.com/PrefsCuritiba.

\section{Estágio 2}

a) Grupo: Serviço

fontes: Ferrer e Santos (2004); Laudon e Laudon (2013); Zugman (2006); modelos analisados

- Requisito: Disponibilizar meios para contato, como e-mails ou formulários do próprio sítio;

- Detalhamento: Possibilitar ao usuário o contato com o órgão para uma dúvida, reclamação, sugestão, e pré-agendamentos ou solicitação de serviços. Ex.: O usuário entra em contato e agende um horário para comparecer em uma secretaria para ser atendido.

b) Grupo: Acessibilidade

fontes: WCAG (2014); Brasil (2014)

- Requisito: Legendas pré-gravadas para áudio;

- Detalhamento: São fornecidas legendas para todo o conteúdo áudio pré-gravado presente no conteúdo multimédia sincronizado (exceto quando o conteúdo multimédia for um alternativo ao texto) apresentandose assim claramente identificado como tal. Ex.: Um áudio possui o arquivo com a legenda do que está sendo transmitido.

c) Grupo: Usabilidade

fontes: Brasil (2014b); Brasil (2009)

- Requisito: Elementos da identidade visual localizados sempre no mesmo lugar;

- Detalhamento: Elementos comuns a todas as páginas, como logotipos, atalhos e caixas de busca, devem estar sempre no mesmo lugar. Ex.: A barra de funcionalidades sempre se encontra no lado esquerdo da página.

d) Grupo: Rede social

fontes: Dziekaniak (2012); modelos analisados

- Requisito: Consulta aos cidadãos sobre sua satisfação a respeito das plataformas e-Gov existentes;

- Detalhamento: Existência de consultas a respeito dos serviços prestados ou sugestões para novas propostas. Ex.: Enquete para descobrir os serviços que deveriam ser oferecidos na rede social.

\section{Estágio 3}

a) Grupo: Serviço

fontes: Ferrer e Santos (2004); Laudon e Laudon (2013); Zugman (2006); modelos analisados

- Requisito: Disponibilizar serviços totalmente online, em que é efetuada a solicitação, atualizado o acompanhamento e finalizado com a pesquisa de satisfação do usuário; 
- Detalhamento: Possibilita o usuário a contatar o órgão para uma dúvida, reclamação, sugestão, e préagendamentos ou solicitação de serviços. Ex.: O usuário entra em contato e agende um horário para comparecer em uma secretaria para ser atendido.

b) Grupo: Acessibilidade

fontes: WCAG (2014); Brasil (2014)

- Requisito: Redimensionar texto;

- Detalhamento: O texto pode ser redimensionado sem tecnologia de apoio (como a lupa do sistema operacional) até $200 \%$ sem perder conteúdo ou funcionalidade (com exceção para legendas e texto sob a forma de imagem). Ex.: A página com texto possui um botão que permite aumentar o tamanho das letras deste texto.

c) Grupo: Usabilidade

fontes: Brasil (2014b); Brasil (2009)

- Requisito: Documentação, tutorial e mapa do sítio;

- Detalhamento: O sítio deve fazer uso de tutoriais e auxílios à navegação, tais como um mapa do sítio ou índice de palavras de A a Z. Os conceitos e termos utilizados devem estar bem explicados. Ex.: O sítio possui a funcionalidade "Mapa do sítio" que apresenta toda a sua estrutura de páginas.

d) Grupo: Rede social

fontes: Dziekaniak (2012); modelos analisados

- Requisito: Disponibilizar e divulgar, amplamente à sociedade como um todo, as experiências e as melhorias que já foram implementadas, quais ainda serão - com prazos estipulados e quais, no momento, apesar de identificadas como necessárias pelas redes sociais consultadas, ainda não serão possíveis de realizar;

- Detalhamento: Todas as ações do governo são divulgadas nas redes sociais, bem como as ações futuras e os resultados das expectativas dos cidadãos mediante extração de dados das redes sociais. Ex.: O governo identificou uma demanda dos cidadãos nas redes sociais mas não conseguirá executá-la. Tanto essa identificação quanto o motivo do impedimento de execução são apresentados na página oficial.

\section{Estágio 4}

a) Grupo: Serviço

fontes: Ferrer e Santos (2004); Laudon e Laudon (2013); Zugman (2006); modelos analisados

- Requisito: disponibilizar ferramentas para interação entre usuários, possibilitando a conexão entre diferentes interessados, como: governo, setor privado; instituições acadêmicas e organizações não governamentais;

- Detalhamento: Um ambiente colaborativo em que os diversos interessados possam interagir entre si e trocar experiências ou fazer negócios. Ex.: Um empresário de uma construtora entra em contato com outros empresários que fabricam matéria-prima e com prestadores de serviços em obras.

b) Grupo: Acessibilidade

fontes: WCAG (2014); Brasil (2014)

- Requisito: Linguagem de sinais (Pré-gravada);

- Detalhamento: É fornecida interpretação em língua gestual para todo o conteúdo de áudio pré-gravado presente de maneira sincronizada. Ex.: Uma mídia de áudio possui um vídeo de linguagem de sinais do conteúdo apresentado.

c) Grupo: Usabilidade

fontes: Brasil (2014b); Brasil (2009)

- Requisito: Teclado (sem exceção);

- Detalhamento: Toda a funcionalidade do conteúdo é operável por meio de uma interface de teclado. Ex.: O tópico de ajuda pode ser acessado com a tecla F1 do teclado.

d) Grupo: Rede social

fontes: Dziekaniak (2012); modelos analisados 
- Requisito: Disponibilizar um ambiente de compartilhamento de conteúdos, que possibilite, tanto ao governo, quanto aos cidadãos, postar conteúdo colaborativo a respeito de sugestões, reclamações, proposição de soluções, exemplos de melhores práticas e conhecimento sobre desenvolvimento e avaliação de plataformas e-Gov;

- Detalhamento: Construir neste espaço colaborativo uma ferramenta a exemplo dos fóruns sociais existentes para que, tanto cidadãos, quanto governo possam se comunicar interativamente e em tempo real. Ex.: Um cidadão cria um tópico com uma dúvida, que outros cidadãos comentam seus pontos de vista e o próprio órgão transmite a resposta oficial.

Cada estágio do modelo, com exceção do primeiro/inicial, é alcançado a partir do cumprimento do estágio anterior. Isto corresponde ao modelo de maturidade do CMM, em que os níveis são sequenciais e a forma de enquadramento em um determinado nível é possível após o cumprimento do nível anterior, com exceção -como já citado - do nível inicial.

\section{CONSIDERAÇÕES FINAIS}

Foi possível constatar que modelos de maturidade são instrumentos importantes para a gestão de organizações e desta forma um modelo de maturidade para governo eletrônico pode vir a ser um auxílio para gestão de governo.

Um modelo de maturidade proporciona uma metodologia para avaliação da situação atual, na qual, por exemplo, uma organização se encontra frente ao que se está avaliando. É uma ferramenta essencial para retratar a realidade de um processo, objeto ou situação e propor diretrizes para sua melhoria. O modelo proposto avalia a maturidade do governo eletrônico e, portanto, seu objetivo é demonstrar a classificação de um sítio de governo eletrônico nos estágios previstos. Esta classificação permite o conhecimento das necessidades e aperfeiçoamentos possíveis tanto para o sítio progredir na classificação dentro do modelo de maturidade quanto para proporcionar melhorias para seus utilizadores.

A criação de um modelo frente a outros já existentes é resultado do estudo bibliográfico sobre o tema de modelos de maturidade para governo eletrônico no qual apresenta previsão de avaliação para as matérias de acessibilidade e usabilidade em internet face às recomendações do governo brasileiro bem como integração com redes sociais e disponibilização de serviços públicos aos cidadãos.

Como propostas futuras recomenda-se a elaboração de um instrumento para classificação de sítios de governo eletrônico a partir de indicadores de requisitos presentes em cada estágio do modelo. A estes indicadores podem ser atribuídas pontuações que permitirão a contabilização daqueles atendidos e a classificação do sítio em análise. Em artigo futuro será desenvolvido estudo para elaboração destes indicadores de requisitos para cada estágio de acordo com os grupos sugeridos neste artigo e acompanhado de estudo piloto. 


\section{REFERÊNCIAS}

Alhomod, S. M., \& Shafi, M. M. (2012). Best practices in e-government: a review of some innovative models proposed in different countries. International Journal of Electrical and Computer Sciences, 12(1), 1-6. Recuperado de http://www .ijens.org/vol_12_i_01/122001-7878-ijecs-ijens.pdf

Almazan, R. S., \& Gil Garcia, J. R. (2008). E-government portals in Mexico. Recuperado em 14 set. 2014, de http://www.igi-global.com/chapter/electronic-government -concepts-methodologies-tools/9818

Andersen, K. V., \& Henriksen, H. Z. (2002). E-government maturity models: extension of the Layne and Lee model. Government Information Quarterly, 23(2), 236-248. Recuperado de http://dx.doi.org/10.1016/j.giq.2005.11.008

Araújo, E. N. (2007). Curso de direito administrativo (3a. ed.). São Paulo: Saraiva.

Barbosa, J. L. (2010). Política pública, gestão municipal e participação social na construção de uma agenda de direitos à cidade. Scripta Nova: Revista electrónica de geografía y ciencias sociales, 14(331). Recuperado de http://www.ub.edu/geocrit/ sn/sn-331/sn-331-51.htm

Baum, C., \& Di Maio, A. (2000). Gartner's four phases of e-government model. Recuperado em 28 set. 2014, de https://www.gartner.com/doc/317292/gartners-phases -egovernment-model

United Nations. (2012). E-government survey 2012: egovernment for the people. Recuperado em 11 nov. 2014, de http://unpan1.un.org/intradoc/groups/public/documents/ un/unpan048065.pdf

Brasil. (2009). Padrões web em governo eletrônico: guia de administração. Brasília: SLTI. Recuperado de http://epwg .governoeletronico.gov.br/cartilha-usabilidade

Brasil. (2014). eMAG: Modelo de acessibilidade em governo eletrônico. Brasília: SLTI.

Brasil. (2014b). GOVBR. governo eletrônico brasileiro. Recuperado em 14 nov. 2014, de http://governoeletronico.gov.br/

Carnegie Mellon University. (2006). Software Engineering Institute. CMMI para Desenvolvimento - versão 1.2: melhoria de processos visando melhores produtos. Recuperado em 20 jun. 2015, de http://www.sei.cmu.edu/library/assets/ whitepapers/cmmi-dev_1-2_portuguese.pdf

Castells, M. (2002). A sociedade em rede (6a. ed.). São Paulo: Paz e Terra.

Chahim, A., Cunha, M. A., Knight, P. T., \& Pinto, S. L. (2004). E-Gov.Br: a próxima revolução brasileira. São Paulo: Pratice Hall.

Chandler, S., \& Emanuels, S. (2002). Transformation not automation. In Proceedings of 2nd european conference on e-government (p. 91-102). United Kingdom. Recuperado em 18 set. 2014, de http://books.google.com/ books?hl=en \&lr=\&id=3YZP9nBw7AUC \&oi=fnd \&pg= PA92 \&dq=Transformation+not+automation \&ots= aFmYqHoV3x \&sig=61L6hnIMq50kPKoh9ujsdITEDD4

Chen, J., Yan, Y., \& Mingins, C. A. (2011). Three-dimensional model for e-government development: with dases in China's regional e-government practice and experience. In Management of e-Commerce and e-Government (p. 113-120). Hubei, China. Recuperado em 20 set. 2014, de http://ieeexplore.ieee .org/xpls/abs_all.jsp?arnumber=6092643

Cisco Systems Inc. (2008). E-government best practices learning from success, avoiding the pitfalls. Recuperado em 15 set. 2014, de http://siteresources.worldbank.org/ EXTEDEVELOPMENT/Resources/20080222_Phil_eGov _workshop.pdf?resourceurlname=20080222_Phil_eGov -workshop.pdf

Deloitte Touche. (2000). At the dawn of eGovernment: The citizen as customer. Government Finance Review, 16(5). Recuperado em 9 nov. 2014, de https:/www.questia.com/magazine/1G1-67323089/ at-the-dawn-of-e-Government-the-citizen-as-customer

Di Pietro, M. S. Z. (2012). Direito administrativo (25a. ed.). São Paulo: Atlas.

Dziekaniak, G. V. (2012). Método para inclusão de conhecimento presente em mídias sociais no aprimoramento de plataformas de governo eletrônico (Doutorado em Engenharia e Gestão do Conhecimento, Universidade Federal de Santa Catarina, Florianópolis). Recuperado de http://repositorio .ufsc.br/xmlui/handle/123456789/100908

Ferrer, F., \& Santos, P. (2004). E-Government: o governo eletrônico no Brasil. São Paulo: Saraiva.

Guerreiro, E. P. (2006). Cidade digital: infoinclusão social e tecnologia em rede. São Paulo: SENAC.

Hiller, J. S., \& Belanger, F. (2001). Privacy strategies for electronic government. In M. Abramson \& G. E. Means (Eds.), E-government 2001: IBM endowment for the bussiness of government. USA: Rowman \& Littlefield Publishers.

Howard, M. (2001). E-government across the globe: how will 'e' change government. Government Finance Review, 17(4). Recuperado em 2 nov. 2014, de https://www.questia.com/magazine/1G1-78902832/ e-Government-across-the-globe-how-will-e-change

Kim, D. Y., \& Grant, G. (2010). E-government maturity model using the capability maturity model integration. Journal of Systems \& Information Technology, 3(12), 230-244. Recuperado de http://dx.doi.org/10.1108/13287261011070858

Laudon, K. C., \& Laudon, J. P. (2013). Sistemas de informação gerenciais (9a. ed.). São Paulo: Pearson Pretice Hall.

Layne, K., \& Lee, J. (2001). Developing fully functional egovernment: a four stage model. Government Information Quarterly, 2(18), 122-136. Recuperado de http://dx.doi.org/ 10.1016/S0740-624X(01)00066-1

Lee, G., \& Kwak, Y. H. (2012). An Open Government Maturity Model for social media-based public engagement. Government Information Quarterly, 29(4), 492-503. Recuperado de http://dx.doi.org/10.1016/j.giq.2012.06.001

Meirelles, H. L. (1996). Direito municipal brasileiro (8a. ed.). São Paulo: Malheiros.

Moon, M. J. (2002). The evolution of e-government among municipalities: rhetoric or reality? Public Administration Review, 4(62), 424-433. Recuperado de http://dx.doi.org/ $10.1111 / 0033-3352.00196$

Netchaeva, I. (2002). E-government and e-democracy a comparison of opportunities in the north and south. International Communication Gazette, 5(64), 467-477. Recuperado de http://dx.doi.org/10.1177/17480485020640050601

Paula Filho, W. d. (2011). Engenharia de software: fundamentos, métodos e padrões. Rio de Janeiro: LTC.

Reddick, C. G. (2004). A two-stage model of e-government growth: theories and empirical evidence for US cities. Government Information Quarterly, 1(21), 51-64. Recuperado de http://dx.doi.org/10.1016/j.giq.2003.11.004

Rezende, D. A. (2012). Planejamento de estratégias e infor- 
mações municipais para cidade digital: guia para projetos em prefeituras e organizações públicas. São Paulo: Atlas.

Rohleder, S. J., \& Jupp, V. (2003). E-government leadership: engaging the customer. Recuperado em 4 nov. 2014, de http://nstore.accenture.com/acn_com/PDF/Engaging_the Customer.pdf

Santos, R. d. L. (2002). Governo eletrônico: o que se deve e o que não se deve fazer. Recuperado em 10 nov. 2014, de http://www.egov.ufsc.br/portal/sites/default/files/ anexos/5694-5686-1-PB.pdf

Shahkooh, K. A., Saghafi, F., \& Abdollahi, A. (2008). A proposed model for e-government maturity. In Information and communication technologies: from theory to applications (p. 1-5). Damasco, Síria. Recuperado de http://ieeexplore .ieee.org/xpls/abs_all.jsp?arnumber $=4529948$

Siau, K., \& Long, Y. (2005). Synthesizing e-government stage models-a meta-synthesis based on meta-ethnography approach. Industrial Management \& Data Systems, 4(105), 443-458. Recuperado de http://dx.doi.org/10.1108/ 02635570510592352

United Kingdon. (2002). Government on the web II. Recuperado em 14 nov. 2014, de http://www.nao.org.uk/ publications/0102/government_on_the_web_ii

WCAG. (2014). Diretrizes de acessibilidade para conteúdo web. Recuperado em 11 nov. 2014, de http://www.w3.org/ Translations/WCAG20-pt-br/

Wescott, C. G. (2001). E-government in the Asia-pacific region. Asian Journal of Political Science, 2(9), 1-24. Recuperado de http://dx.doi.org/10.1080/02185370108434189

West, D. M. (2004). E-government and the transformation of service delivery and citizen attitudes. Public Administration Review, 1(64), 15-27. Recuperado de http://dx.doi.org/10 .1111/j.1540-6210.2004.00343.x

Windley, P. J. (2002). Egovernment maturity. Recuperado em 14 nov. 2014, de http://www.windley.com/docs/ eGovernmentMaturity.pdf

Zugman, F. (2006). Governo eletrônico: saiba tudo sobre essa revolução. São Paulo: Livro Pronto.

Como citar este artigo (APA):

Lechakoski, R. M. \& Tsunoda, D. F. (2015). Proposta de um modelo de maturidade para sítios de governo eletrônico. AtoZ: novas práticas em informação e conhecimento, 4(1), 43 - 54. Recuperado de: http://dx.doi .org/10.5380/atoz.v4i1.42319 